\title{
CAPABILITIES IN KNOWLEDGE-BASED REGIONAL DEVELOPMENT - TOWARDS A DYNAMIC FRAMEWORK
}

\section{Valtteri Laasonen and Jari Kolehmainen}

Faculty of Management, Urban and Regional Studies Group SENTE, University of Tampere, Tampere, Finland

Correspondence Address: Valtteri Laasonen, Faculty of Management, Urban and Regional Studies Group SENTE, University of Tampere, Kanslerinrinne 1, 33014 Tampere, University of Tampere, Finland.Email: valtteri.laasonen@uta.fi, Phone: $+358505330604$

Acknowledgements:

This piece work was a part of ITU research programme (ITU, Local and Regional Innovation Environments) funded by University of Tampere, Regional Council of South Ostrobothnia, City of Seinäjoki, Into Seinäjoki Ltd., University Consortium of Seinäjoki and Higher Education Fund of South Ostrobothnia. We would like to acknowledge the support of professor Markku Sotarauta for his comments on the earlier drafts of this article. 


\section{CAPABILITIES IN KNOWLEDGE-BASED REGIONAL DEVELOPMENT - TOWARDS A DYNAMIC FRAMEWORK}

There are only a few studies dealing with capabilities in the knowledge-based regional development and especially in the implementation of contemporary innovation policy. Drawing upon the resource-based view, the capability perspective identifies combinations of regional resources and capabilities that generate competitive advantage. In light of theoretical and empirical advancement, this paper introduces a capability framework to reveal the multi-layered and dynamic nature of capabilities in knowledge-based regional development. The paper argues that in the regional context, it is important to consider and analyse 1) the organizational level resource and knowledge base and 2) ways in which the regional networks of organizations, engaged in knowledge-based development activities, exploit and renew regional resources and capabilities. The empirical analysis is based on personal in-depth interviews and document analysis. The findings indicate that studies on knowledge-based regional development should pay more attention to the capabilities of the actors involved in development processes. Innovation policy should be viewed as a means to mobilize, renew, build and acquire new resources and capabilities in a region and should aim to build and stimulate regional networklevel capabilities for economic renewal.

Keywords: innovation policy, resource-based view, capability, regional development, network 


\section{Introduction}

Over the last two decades, the pursuit of a 'knowledge-based economy' has become a prime goal for economic development across European countries, and 'knowledgebased regional development' strategies are widely adopted by regions as a means to achieve this goal. Scholarly debate originates from various territorial innovation models (TIMs), especially the regional innovation system (RIS), which have been major conceptual frameworks for understanding knowledge-based and innovation-driven regional development. The literature has emphasized the notion that economic renewal and regional competitive advantage may reside in the RIS and also, as an implication, the need to implement policies that strengthen and develop the system itself. Influenced by the resource-based view of the firm (Barney, 1991; Hamel \& Prahalad, 1996; Penrose, 1959; Wernerfelt, 1984), a stream of literature has formed, examining and underlining the role of regional resources and capabilities in developing locationspecific competitive advantage (e.g. Boschma, 2004; Cooke, 2007; Lawson, 1999; Lawson \& Lorenz, 1999; Maskell \& Malmberg, 1999; Pihkala, Harmaakorpi, \& Pekkarinen, 2007).

Following this idea, the resource-based view provides a useful framework to study and analyse knowledge as a key resource and capabilities of regional economic actors and networks to sustain, renew and create new knowledge and foster innovation in the regional context. Besides stressing the role of the firm- or organization-level capabilities, it is important to recognize the embedded and multi-layered nature of regional capabilities that are needed in complex development and policy processes.

However, the role of capabilities has been overshadowed, especially in the structural analysis of innovation systems and policies (see e.g. Carlsson, 2007). From the policy perspective, the static view on the regional structures and institutional 
settings is not enough without knowing what actually happens in the system and is achieved in functional terms (see e.g. Bergek, Jacobsson, Carlsson, Lindmark, \& Rickne, 2008). This paper argues that the capability perspective combines the view on system structures (components and their relationships) and the processes that are needed in the regional development processes. Therefore, the paper aims at developing a dynamic framework for analysing and identify the capabilities in the knowledge-based regional development, and especially in the processes of shaping and executing innovation policies in the regional context. The idea is also to show that there is something beyond the firm- and organization-level resources and capabilities. We call these activities network-level capabilities, which can be seen as a collective learning process across regional organizations.

With the help of the above-mentioned framework and our empirical data, we recognized the most valuable qualities in regional resources and identified the capability sets which form the basis for the most important development processes. These general and ideal capability sets reflect our interviewees' impressions of highly valuable and essential resources and qualities that the contemporary innovation policy requires from the actors involved in these processes. The empirical context of this paper is Finland and its innovation policies which simultaneously have both the national and the regional dimension.

The article is structured as follows. The following section presents the key issues and characteristics of the knowledge-based regional development policies and then the key ideas stemming from the resource-based view and the capability literature are introduced. In the third section, we introduce the research design and methods. On the basis of preceding theoretical notions, the fourth section introduces a theoretical capability framework for the empirical analysis represented in the fifth section. The 
final section summarizes the key findings and discusses the applicability and the consistency of the developed capability framework. In addition, some suggestions for further research are presented.

\section{The Role of Capabilities in Knowledge-Based Regional Development}

The need to understand the nature and sources of economic growth and related success factors has produced an extensive body of research on the dimensions and dynamics of regional innovation activities and policies (Carlsson, 2007; Fagerberg \& Verspagen, 2009). Scholarly debate on 'knowledge-based regional development' originates from territorial innovation models (see Moulaert \& Sekia, 2003). In particular, regional innovation system literature has revealed the role of innovation, localized learning, knowledge spill-overs, institutions and networks in the regional development and economic performance (Cooke, 1992, 2001; Freeman, 1987; Lundvall, 1992). The literature has emphasized the notion that economic renewal and regional competitive advantage may reside in the regional innovation system. RIS has also become a dominant analytical and policy concept within the regional policy discourse, stressing the need to implement policies to strengthen and renew the innovation system itself (Uyarra \& Flanagan, 2010).

\section{The Nature of Knowledge-Based Regional Development}

As we refer to the knowledge-based regional development, two aspects are especially stressed here. Firstly, knowledge-based regional development puts emphasis on the key role of knowledge and innovation and policies that foster innovation and economic prosperity of a region, i.e. innovation policy (see e.g. Cooke \& Leydesdorff, 2006;

Dahlström \& James, 2012). Secondly, we pay attention to the nature and the way in which this innovation policy is formulated and implemented. In this respect, the 
collaboration between various economic actors and a wide range of actions are the key aspects.

In his definition, Edquist (2011, p. 1725) states that innovation policy involves actions by public organizations that influence innovation processes. Innovation policy is usually seen to consist of explicit measures to promote the development, diffusion and efficient use of new products, services and processes in markets or various organizations (Lundvall \& Borrás, 2005, p. 37). However, developed and more comprehensive understanding of innovation activities and theoretical rationales for public intervention to affect innovation have suggested a broader view on innovation policy. The studies on innovation policy highlight the shift from traditional market failure approach to broader system failure (Edquist, 1997) and more recently the transformational system failure approach (Weber \& Rohracher, 2012). This broader definition considers the innovation policy as a systemic and broad-based activity. The main emphasis is on the entire system of innovation and a wide range of initiatives that are linked to science and technology and both supply and demand for innovation (Edquist, Luukkonen, \& Sotarauta, 2009). The systemic rationales have proposed a more proactive role for a government to intervene and expand their areas of involvement. These ideas have also introduced customization of innovation policies and suggested more role for knowledge-based regional development. The recent developments reflect the ideas about the distribution of power, multi-level, multi-actor governance and the New Public Management (Flanagan, Uyarra, \& Laranja, 2011). Growing interest in regional systems of innovations and policies support the view that the promotion of regional economic development is an interactive process between and among firms, various public or semi-public development agencies and research institutions. This network paradigm emphasizes the interdependence of public 
and private activities and suggests that the knowledge-based regional development should have a stronger focus on actors, agencies and their interaction and governance forms (Cooke \& Morgan, 1998; Flanagan et al., 2011, p. 811; Laranja, 2012; Morgan, 1997). This implies that there should be a stronger focus on the capabilities and potential of diverse regional actors, including firms, municipalities, technology centres, development organizations, research and education organizations, funding agencies etc., contributing to regional development (Cooke, 2007). Yet, a number of scholars have noted a striking neglect of agency in the regional development and innovation policy literature (Markusen, 2003; Uyarra, 2010).

The network approach to knowledge-based regional development processes help us reveal the importance and multi-level nature of capabilities in regional development and also grasp the contexts in which complex development processes take place. Uyarra and Flanagan (2010, p. 688) provide a good point of departure for the understanding of regional development and policy processes. They regard regions as 'spaces for the mobilization of resources, priority setting, institutional creation, policy coordination, and governance, as well as policy learning and capacity building'. Regional level policy-making processes should be understood as 'a complex interplay of many actors across different levels of policy, including non-state actors (e.g. firms), nongovernmental organizations, professions and other actors, engaged in a collective process of negotiation and compromise' (Uyarra, 2010, p. 131).

Widening and deepening of the innovation policy (see Borrás, 2009) has transformed the scope and the form of public intervention in innovation processes. Therefore, this phenomenon has brought new requirements for the capabilities of public sector organizations in shaping and exercising the innovation policy. For example, the 
understanding of the actual market processes is even more vital as well as the capabilities to foster the demand side of innovation.

In summary, the literature review suggests that knowledge-based regional development is a complex interplay of different actors and a wide range of actions. It also requires good networks between different actors and interrelated capabilities widely distributed within the networks that are formulating and executing the regional innovation policies.

\section{Resource-Based View and Capability Perspective in Regional Analysis}

The study on the role of capabilities in regional economic development and renewal originates from a resource-based view of the firm (Barney, 1991; Penrose, 1959; Wernerfelt, 1984), which has also been complemented by the dynamic capabilities framework (Teece, Pisano, \& Shuen, 1997). This approach has been widely applied in organization and management studies, but there are also some applications in the field of innovation and regional studies. Thus, it is relevant to elaborate the key arguments developed in the both fields. In organization and management studies, a significant number of recent contributions draw upon (core) competences (e.g. Prahalad \& Hamel, 1990; Javidan, 1998), capacities, capabilities or dynamic capabilities of the firm (e.g. Teece et al., 1997; Wang \& Ahmed, 2007). This capability (or competence) perspective has identified ways in 'which competitive advantage may be obtained through a superior ability to coordinate flows of intellectual assets and other resources within and between firms that function like open systems' (Sanchez \& Heene, 1997, p. 304).

A conception of firms as heterogeneous accumulations of resources has guided the development of the resource-based approach. These distinctive resource endowments are also sought to explain differences in firm performance. Within evolutionary economics, Nelson and Winter (1982) introduced a similar focus on 
distinctive capabilities of firms by stressing organizational routines to explain the survival of a firm in a changing competitive environment. Thus, the idea in the capability perspective is to focus on organizations' internal dynamics and processes defined by the organization's unique resources and capabilities and link them to external strategic interactions and performance (Sanchez \& Heene, 1997).

Drawing from these insights, there are varied ways of how the capability perspective has been discussed and applied in the regional context. The role of capabilities has been loosely referred in regional studies and linked to the importance of developing a location-specific competitive advantage (see Uyarra, 2010, p. 117). However, the central idea in applying resource-based view in the regional context is that regional accumulation of resources and capabilities provide a competitive advantage against other regions. Scholars like Storper (1997), Lawson (1999), Maskell and Malmberg (1999), Boschma (2004), Harmaakorpi (2004), Cooke (2007) and Borrás and Edquist (2013a) reflect on the idea of the resource-based view in the regional context. These studies suggest that competitive advantage is linked to (unique) knowledge resources and especially localized knowledge creation processes and capabilities of actors to utilize resources. Another perspective has been to study dynamic capabilities to renew the regional resource base and capabilities (e.g. Pihkala et al., 2007).

Despite the conceptual heterogeneity, there is much value in extending the firmlevel capability perspective to the regional level analysis (e.g. Boschma, 2004; Lawson, 1999; Uyarra, 2010, pp. 117-118). As Lawson (ibid.) stresses, it is the regional set of capabilities within which the firms' activities also need to be understood and assessed. Firms and regions both consist of capabilities that are the emergent properties of social activity. Therefore, according to Lawson (1999), a fundamental issue to distinguish between capabilities of firms and regions is to identify the manner in which the 
interaction is reproduced or transformed. He (ibid.: 157) suggests that regional capabilities emerge from and are reproduced through the interaction of agents and this interaction 'stretches both through space and across organizations, and contains a degree of coherence in virtue of the nature of (localized) interaction'.

Capabilities in knowledge-based development do not, of course, explain the whole picture of the competitive advantage of regions (Boschma, 2004, p. 1005). Moreover, the role of local environment should be analysed critically in innovation processes, and one should be careful not to overestimate its role (Kolehmainen, 2016). This implies that many geographical scales are involved in interactive learning processes at the same time (Malmberg \& Maskell, 2002). Nonetheless, this notion does not take away the relevance of the regional perspective. As Boschma (2004, p. 1004) states, despite the fact that regions do not compete in the same way as firms (enter and exit markets), 'to an increasing extent regions are active players representing regional interests, with the goal of preserving or enhancing their competitiveness'. In addition, regional strategies, policy-making and the capacity to coordinate the actions of regional organizations, i.e. innovation policy, can influence the performance of a region.

As the study on the (regional) innovation system suggests, the capabilities of firms are shaped in interaction with the resources, structures and institutions of the location region (Lundvall, 1992; Cooke, Uranga, \& Etxebarria, 1997). Maskell and Malmberg (1999) refer to the interaction with localized capabilities, which are based on the region's infrastructure, built environment and natural resources, the region's specific institutional endowments and the knowledge and skills available in the region. Thus, regions provide resources and access to local and non-local information and also influence how resources (especially tacit knowledge) and capabilities are accumulated, reproduced and recombined through actions and interactions of local agents (Boschma, 
2004, p. 1006). In this sense, some systems of interaction are better and more competent at facilitating certain processes than others. Natural and physical resources are still important, but even more emphasis is put on the key role of knowledge as a resource and capabilities to foster innovation.

Regional resources and capabilities also have a path-dependent nature. From the evolutionary perspective, these different resources and capabilities are accumulated over time, which also affects the competitiveness of firms and creates different regional trajectories (see Boschma, 2004, p. 1008; Martin \& Sunley, 2006). Consequently, the role of innovation policy is to develop these resources and capabilities. On the other hand, capabilities of policymakers are required to renew these resources and capabilities.

Yet, a framework and methods of how to analyse these multi-layered capabilities, and what and whose capabilities are needed in the regional knowledgebased development has remained somewhat abstract and vague both in the field of research and practical policy-making. There is still not much analysis or discussion of who and how different actors contribute to the functioning and performance of these systemic development processes (Borrás \& Edquist, 2013b; Carlsson, 2007; Carlsson, Jacobsson, Holmén, \& Rickne, 2002). Thus, it is important to investigate how regional actors are capable of influencing regional development and shape, interpret and exercise innovation policy (see also Sotarauta \& Kosonen, 2013).

\section{Research Design and Methods}

In this study, we focus on the capabilities of the networks of regional actors which contribute to knowledge-based regional development and play a key role in shaping and directing innovation policy. In Finland, these networks consist of the local government (municipalities), regional business development agencies and technology centres, 
Regional Councils (local government development agency at the regional level), Employment and Economic Development Centres (state development agency at the regional level), higher education institutes (HEIs), other research and education organizations etc.

The empirical analysis is based on qualitative research methods and data. Personal in-depth interviews have been the main data source and set of policy documents was the secondary data source including 20 main Finnish national innovation policy documents (such as strategies and policy guidelines and) and innovation policy evaluation from the 2000's. The interview data was gathered through 13 semi-structured interviews with Finnish actors responsible for preparation of national innovation strategy and implementation of national innovation policy. Thus, the set of recognized capabilities represent national expectations of what the implementation of innovation policy should be like in regional networks, and what attributes and qualities the contemporary innovation activity and policy require from the actors involved in the knowledge-based regional development processes. It should be noted that in Finland, national policies and these capability expectations are formulated through a coevolutionary process between national and regional/local levels (Sotarauta \& Kautonen, 2007).

The interviewees represent key organizations and bodies like the Research and Innovation Council of Finland, the Ministry of Employment and the Economy, business confederations, the Finnish Funding Agency for Technology and Innovation, the Finnish Innovation Fund and regional councils. Discussion with the interviewees included a broad discussion concerning the most important changes of innovation policy, the nature of contemporary innovation activities and their implications to the implementation of innovation policy. Moreover, the discussion dealt with the most 
essential activities in regional innovation policy and the most important resources and capabilities related to them. The interviews were conducted in Finnish between April and May 2015 and were recorded and transcribed. Important quotes were translated into English by the authors.

\section{Constructive Synthesis of the Capability Framework}

In the following, we introduce our own elaboration of a theoretically driven capability framework based on the literature review. In the next chapter, we elaborate our empirical findings by using the framework. The framework and our empirical findings do not imply that introduced capability sets emerge identically in every region, rather, on the contrary. We in particular propose that resources and these general and ideal capability sets occur in unique combinations in every region that proactively construct the competitive advantage of a region. This ideal model is a construct of capabilities that are seen as highly valuable and essential activities in innovation policy and what regional actors should be good at as a network when considering knowledge-based regional development.

Wang and Ahmed (2007) propose a hierarchical capability structure where each level is a product of lower-level attributes. Thus, resources are seen as 'zero-order' and capabilities as 'first-order' elements, meaning that resources are deployed by capabilities (see Vesalainen \& Hakala, 2014). In our framework (Figure 1), the basis of network-level capabilities is formed by organization-level resources and capabilities. This means that resources and capabilities are owned or implicitly/explicitly 'controlled' by individual regional organizations. Correspondingly, network-level capabilities refer to regional networks' ability to exploit and combine resources and capabilities of different organizations, through different activities and processes (cf. Amit \& Schoemaker, 1993). Resources are divided in two categories, tangible and 
intangible resources, which are organization-specific basic elements. Tangible resources include, e.g., people, money and location-specific physical resources (geographical location, built environments etc.), and intangible resources consist of diverse skills and knowledge capital, relational capital (social relationships, brand) and structural capital (values, culture, instruments etc.). To make a distinction between resources and capabilities, network-level capabilities in our framework are those which connect the widely distributed resources within a region and activities that unleash the full potential of the resources and attributes (cf. Amit \& Schoemaker, 1993, p. 35; Vesalainen \& Hakala, 2014, p. 939). One important notion is that the capability to exploit resources is not restricted only to a bounded regional context, but attention should be paid also on regional networks' capability to deploy resources and capabilities from elsewhere as well, both nationally and internationally.

Figure 1. The capability framework for analysing knowledge-based regional development.

In firm-level studies, this unique combination of resources and capabilities that are valuable, rare, difficult to imitate and substitute form a foundation for sustainable competitive advantage of a firm (Wang \& Ahmed, 2007). In our framework, core capabilities are simply understood as bundles of resources and capabilities, which are built up over time. Thus, these region specific capabilities are hard to copy or imitate by other regions (see also Boschma, 2004, p. 1007). Core capabilities can be described as a collective learning process across regional networks, and thus, much more than simply what an individual organization is good at (cf. Prahalad \& Hamel, 1990). The question is about how different functions and processes that support innovation activities emerge or are transformed into strategic capabilities that consistently sustain, renew and/or 
create new knowledge and businesses in regions. The actions of different innovation policy actors are constantly shaped through interaction with the resources, structures and institutions of the specific region. Furthermore, the widening and deepening of innovation policy (see Borrás, 2009) has affected the idiosyncratic nature of the capabilities of these organizations and networks.

Applying the framework of Wang and Ahmed (2007), dynamic capability is the network's constant pursuit to change the core capability set in relation to the changes in the environment. This means renewal, reconfiguration and re-creation of resources and capabilities (Teece et al., 1997). Thus, Wang and Ahmed (2007) see dynamic capability as the "highest-order" element of the capability hierarchy to influence long-term competitiveness. In our framework, dynamic capabilities are considered as an element embedded in both organizational and network levels as activities and processes as well as those network-level capabilities. On the organizational level, dynamic capabilities occur as the constant pursuit to change an organization's logic and as activities directed for renewal. On the network level, these organization-level dynamic capabilities are exploited and considered as a set of capabilities, how regional networks adapt to changes in environment, absorb and learn and renew regional resources and capabilities as a network (see Boschma, 2004, p. 1010; Harmaakorpi, 2004; Pihkala et al., 2007).

\section{Empirical View on the Capabilities}

\section{Making sense of organizational level resources}

Regional development and innovation activities rest on available resources and knowledge bases exploited by various organizations. Interviewees stressed that knowledge-based regional development requires exploitation of diverse resources and 
knowledge bases. We identified five different categories in organizational level resources:

- regional specific organizational and institutional structures

- versatile, complementary sets of knowledge

- individual talented people

- $\quad$ social capital and cultural factors

- financial assets and physical environment

Firstly, the most obvious perspective is to recognize regional specific organizational and institutional structures, which also distinguish regions from each other. Structural composition analysis of resources should focus on organizations related to knowledge-based development that supports innovation activities, including knowledge suppliers, educational institutions, support infrastructure and specialized services, funding activities and organizations (usually firms) exploiting the knowledge (see also Asheim \& Gertler, 2005; Kautonen, 2006).

The important thing is that there is a lot of different kinds of knowledge in a region, or there are connections to international networks from the region, and the knowledge and contacts are available to those who need them....in innovation activity, we must think of all possible knowledge of what development specific ideas require for new global success products to appear on the market. (Director, Academy of Finland)

Secondly, according to our interviews, an increasingly important issue on the organizational level is to have versatile, complementary sets of knowledge. As recent literature suggests, regions and various industries differ in terms of the type of knowledge that is critical to innovation, and so, it tends to be characterized with different degrees by these knowledge bases (see Asheim, Boschma, \& Cooke, 2011; 
Asheim \& Coenen, 2005; Martin \& Trippl, 2014). The interviewees note that recognition of different knowledge bases and how these are linked to innovation activities and actors in the region is very critical for effective policies (cf. Lönnqvist, Käpylä, Salonius, \& Yigitcanlar, 2014).

The nature of innovation activities has changed, i.e., innovations are more often created by combining different kinds of knowledge and utilizing existing knowledge, as before it was thought that going as deep as possible with one substance is the way. This also emphasizes that those knowledge combinations must be supported. (Expert, Sitra the Finnish Innovation Fund)

Going beyond structural and organizational components, the interviewees emphasized the key role of individual talented people in the knowledge-based regional development. Entrepreneurial and internationally experienced individuals, who have knowledge and experience from various backgrounds in the public and private sector, are seen as valuable resources, i.e., 'people who have seen the world', as one of the interviewees condensed this idea in a few words. The interviewees also highlighted some general knowledge and skills, like networking and communication skills and entrepreneurial attitude, as valuable resources. Our results also support Sotarauta's (2010, p. 391) findings that regional development needs actors and their skills and knowledge in three overlapping categories. The first group is policy generalists who have a spread of general policy interests for a region, a good perception of trends and their significance, and a high level of strategic awareness. The second group is people who understand the subject matter and have deep knowledge of their particular business area. The third group is network managers who understand the process and are able to deal with interactive processes. (ibid.)

Besides knowledge, other intangible resources were also seen as highly valuable. Social capital and cultural factors were referred to in the discussions with 
the interviewees. Local culture that encourages the development of new ideas, new commercial activity and interaction with different actors was seen as a weighty resource. These qualities were seen to be linked to organizations, individuals and collectively to the environment that supports the culture (cf. Saxenian, 1994). There is no arguing that social capital is a key resource in innovation activities (e.g. Martin, 2013; Tura, Harmaakorpi, \& Pekkola, 2008). Strong social capital can also be treated as a capability-like resource in organizations and regions (Pihkala et al., 2007, p. 838) and is closely tied to one of the network-level capabilities introduced later in this article.

Our interviewees also talked about the importance of financial assets and physical environment, 'hot spots', as resources for regional competitive advantage in the sense that these physically pool resources together and create spaces for innovation. Traditionally, this has included and has been understood as compact industrial districts, campus areas, science parks and technology centres. But our interviewees also emphasized the role of financial assets in the form of (remarkable) private and public physical investments and (intelligent) infrastructure as a more and more relevant resource driver for innovation activities. Even more so, now that traditional public R\&D funding and resources in particular have declined in Finland.

\section{Network-Level Capabilities in Regional Knowledge-Based Development}

\section{Processes}

To fully exploit the potential of organizational level resources and knowledge bases, network-level capabilities are needed to connect widely distributed resources within a region. Based on empirical data, we identified three general and interrelated capability sets on the network level. These are:

- network capability

- $\quad$ strategic policy-making capability 
- entrepreneurial capability

Firstly, the most general network-level capability raised by the interviewees here is simply called the network capability. In business economics, network capability is referred to as the ability to build, handle and exploit relationships (Vesalainen \& Hakala, 2014). Knowledge-based regional development is strongly based on networked activities, and innovation activities include co-operation and interaction with various and more diverse set of organizations (Cooke \& Morgan, 1998; Grillitsch \& Trippl, 2014; Pihkala et al., 2007). So, naturally, all interviewees stressed that a prerequisite for organizations involved in innovation activities is the capability to act in networks. In this respect, the international aspect is highly important.

Mobilization and engagement of different key stakeholders and facilitation of multipolar coordination are increasingly emphasized in network-level development processes (see also Sotarauta, 2010, p. 393). Networks are based on trust and reciprocity between individuals and organizations. Thus, essential network-level activity is to build trust between individuals and organizations, i.e., people-centered activities. Common learning and alluring, far-reaching content encourages and stimulates individuals to take part in different meetings, events and development processes. In addition to strong social capital, local and organizational culture was mentioned as an important resource for this activity. Support for long-term interaction between organizations involved in regional innovation activities and inclusive, active dialogic culture and practices in collective forums, meetings and decision-making are seen as very important (cf. Lawson \& Lorenz, 1999).

That 'buzz', that sets innovation activities in motion, always takes place in some context and location...this kind of local collaboration forums and that setting of how interaction takes place are really important; this is where the trust between 
stakeholders is built and communication is, however, the easiest. 'Buzz' is very important in the beginning. (Expert, Sitra the Finnish Innovation Fund)

Our empirical data also indicate that understanding different organizations' viewpoints, needs, language and thinking patterns is a constituent part in the network capability. This is an especially substantive issue to get actors committed, so that they will voluntarily turn their attention, decisions and actions towards a collective goal. The notion of managing in multi-actor networks includes a conciliation of different views and goals. Thus, cognitive aspects and the ability to motivate, empower and inspire stakeholders are important (cf. Ebbekink \& Lagendijk, 2013, p. 747). These qualities are also needed to integrate new actors and knowledge in development processes and to mix knowledge bases. Our results indicate that it is during these processes certain key individuals or network managers who have earned trust between stakeholders are needed to take on a bigger role (cf. Benneworth, 2007; Ingstrup \& Damgaard, 2013; Sotarauta \& Beer, 2015).
It [multilateral collaboration in innovation activities] might very often stop, because there is no capability that brings these actors and firms together and assemble them in a dialogue. That kind of capability is surely emphasized. (Expert, the Ministry of Economic Affairs and Employment)

Secondly and closely integrated to the previous capabilities, the interviewees raised a set of network-level qualities that concern the capabilities to facilitate and effectively implement strategic regional knowledge-based development processes. We call this set of network-level capabilities strategic policy-making capability. The set of capabilities includes activities that engage key stakeholders in collective multi-actor processes of agenda-setting and sense-making to identify development issues and business opportunities in the region. The ideas proposed by the interviewees are quite close to what Ebbekinka and Lagendijka (2013) call the capability to make use of 
"strategic intelligence" - a bottom-up, demand-initiated and negotiated perspective to knowledge-based development strategy and an ongoing, collective, formal and informal strategic dialogue between stakeholders.

Fruitful local development activity embodies strategic thinking, that is, regional actors are capable of building a realistic picture of the strengths and direction of where are we going and what the steps to get there are ... Cold analysis is needed locally of what actors and organizations we have here, what knowledge we have, who we need to have here, what education we need here, what our competitive factors are. This should be done from the region's premises, what the strengths are, and then to invest in them. (Director, Confederation of Finnish Industries)

An important aspect in the strategic policy-making capability is to ask whether we are doing the right thing and whether we are doing things right. These questions have also been noted by Carlsson et al. (2002, p. 235) in their interpretation concerning strategic and functional capabilities of the innovation system. The strategic policymaking capability is collective support and activities in a region for different organizations to direct their own activities (see also Sotarauta, Horlings, \& Liddle, 2012).

The interviewees emphasized the activities to examine the existing resource and knowledge base and also to look forward to what kind of resources and knowledge are needed (cf. Lönnqvist et al., 2014). One pre-requisite is to establish different forums for collective analysis of current and future operational environment and competitive factors. Successful processes require broad engagement of various actors and knowledge from the public, the private and the third sector and explorative approach to develop shared cognitive frames.

Integral quality is also the ability to prioritize, share responsibilities and elaborate actions and roadmaps based on collective analyses. In the public sector 
context, it is important to link different sector policies to support regional strategy and also integrate national and EU-level policies to support required actions. Regional knowledge-based development strategies have to recognize the uniqueness of the region and have to be customized to serve its actors (cf. Sotarauta \& Kosonen, 2013). This requires increasingly good and active communication skills between actors, visionary skills, exploitation of social capital and activities to legitimize regional development processes.

[In regional innovation activities,] I believe in co-operational data analysis and formulation of a common aim and vision and actions based on this kind of process....so the aim is to create shared understanding of the situation and constantly review the plan of action, and through this process, promote a common consensus of what is important and where to direct resources. This is soft leading with information, and that is a kind of important element in this world-wide situation. (Director, Regional Council)

The third capability set is related to a process by which networks of individuals and organizations create opportunities for innovation to comprehend market dynamics building coalitions between public and private sector, exploiting business opportunities and executing actions based on this comprehension. This is what we call the entrepreneurial capability. Competitive advantage is increasingly dependent on the capability to understand global market dynamics and its connections and causal relationships to regional context. A prerequisite for building this comprehension is also an ongoing, collective, formal and informal strategic dialogue between regional stakeholders and outward links from the region especially (see Bathelt, Malmberg, \& Maskell, 2004).

It is increasingly important to build public-private partnerships based on appealing and ambitious visions and take concrete actions that stimulate supply and the 
increasingly demanding side of innovation. The interviewees stressed the role of entrepreneurial capability in activities like new innovative infrastructure investments, public procurement for innovation, innovation competitions and new ways of doing R\&D-projects, to name few. The entrepreneurial attitude in exploiting opportunities was mentioned as crucial both in private, and in the public sector, now more than ever. One practical concern from the interviewees was that without this capability, innovation activities carried out by different public and private organizations would push to opposite directions, are too short-term and region-cantered.

A lot depends on people and their mutual chemistry. This means that it does not need more than a handful of people with power who work, for example, at universities, technology centres, municipalities and companies, and this group starts to do things together and facilitate various meetings in which ideas are born. (Professor, University)

Entrepreneurial capability deserves a lot more attention in regional knowledgebased development and includes new ways of doing things and new resources (knowledge) from many organizations. All interviewees underlined an urgent need of public-sector and R\&D organizations to change their way of supporting innovation activities. For example, a lot more long-term and systemic thinking is needed when the public sector indicates development plans and service needs. Entrepreneurial capability is highly dependent on skills and knowledge to experiment, take risks, act and communicate between various organizations and build new kind of incentives and revenue models. Strong social capital as a resource and activities to strengthen new cooperation relationships are also seen as valuable in this context.

The public sector is involved [in innovation activities] and does what it can, e.g., renewing regulation, building customized infrastructure, doing first public 
procurement for innovation and experiments. This is long-term development. (Expert, Tekes - Finnish Funding Agency for Innovation)

\section{Dynamic Capabilities as Leverage for Region Economic Renewal}

The capabilities introduced in the previous chapter already embody the idea of dynamic capabilities. The interviewees emphasized qualities, embedded in organizational resources and these general network-level capabilities that are crucial in the rapidly changing global environment and volatile economy. These dynamic capabilities are especially seen to resemble regional networks' constant ability to learn, quickly change direction and take actions based on this new knowledge. Networks of organizations with strong dynamic capabilities are more resilient, flexible and capable of generating change and responding to changes in the environment. Carlsson et al. (2002, p. 235) state that change can be generated endogenously by bringing new components (resources, e.g., new actors, knowledge) or by changing the relationships or the attributes among the components (activities to exploit capabilities of actors more intensively, change the nature and intensity of links among actors). Cooke (2005) also refers to dynamic capabilities present at the regional level as helpful when stimulating knowledge transfer.

Our findings supported three perspectives that earlier literature has already noticed in reference to dynamic capabilities. These are:

- absorption

- adaptation

- experimentation

The absorption part of dynamic capabilities resemble regional networks' and their organizations' constant exploration of new knowledge and exploitation of network relationships and outward connections (weak ties) to interpret current and future signals, 
concerning the operational environment and recognize the value of new, external information (cf. Cohen \& Levinthal, 1990; Miguélez \& Moreno, 2015). Thus, a precondition is that knowledge creation processes are not only regional. In addition, knowledge moves within and between organizations and between regional networks and is applied, combined with existing knowledge, and then used to guide actions in these organizations and applied to commercial ends. The mediation of information to the relevant organizations is crucial to take actions. One important aspect is that curiosity towards new knowledge, problem-solving skills, lifelong learning and education is supported and appreciated in different organizations. The effective transfer of knowledge also depends on knowledge brokers, a common language and on shared knowledge amongst organizations in the network (cf. Lawson \& Lorenz, 1999, pp. 306308). Absorption capability plays an important role in avoiding lock-ins and recognizing the bottlenecks in knowledge, and other resources.

We need to have capabilities to identify what concepts there are globally and from where we need to absorb the latest information. (Expert, Tekes - Finnish Funding Agency for Innovation)

Adaptation, by contrast, means that actions are taken based on mutual learning (see Teece et al., 1997). In other words, it means flexibility in common activities to change direction and correct mistakes. On the network level, there must be readiness and a positive attitude towards change and the ability to work with resistance to chance, when something new and radical challenges the present mindsets and way of doing things. These qualities are related to an open organization and network culture and processes that encourage people to step out of their "silos" and give space to passion. Other important aspects are also activities that support the mobility of workforce and a circulation of workers. 
This new way in innovation activities requires us to be capable of coming out of our own boxes and communicating with each other and thinking of common goals. (Expert, the Ministry of Economic Affairs and Employment)

Experimentation is needed in changing circumstances to take appropriate actions and change direction (cf. Eisenhardt \& Martin, 2000, p. 1113; Sotarauta \& Kosonen, 2013, p. 266). Too much planning before acting and experimenting is seen as a hindering element in innovation activities. Today, more and more small trial and error type of activities are needed to get complex innovation processes started. The culture should support these kind of processes, and also publicly funded development processes should support and allow activities that support experimentation. Public policies can do a lot to launch experimentations in cooperation with regional organizations, and public organizations themselves can take the stance as forerunners in applying new technology and act differently themselves. Experimentation and fast pilot-projects, for example, to offer piloting opportunities in multilateral co-operation, are needed in strengthening the regional resource and knowledge base (e.g., to build new infrastructure, institutions and attract new actors).

\section{Conclusion}

The objective of this article was to examine the role of capabilities in knowledge-based regional development and to clarify their multi-layered nature. Moreover, the objective was also to clarify the conceptual heterogeneity and ambiguity concerning capabilities in regional analysis. This task has inevitably involved a recombination of existing ideas and concepts as well as new insights. The results show that there is something beyond organizational capabilities that should be taken into consideration in knowledge-based regional development. Our findings emphasize the fact that regional competitive advantage may reside in organizational level resources and/or in activities and ways in 
which regional networks of organizations, engaged in knowledge-based regional development activities, exploit and renew the resources and capabilities. Consequently, we argue that innovation policy should be seen as a means to mobilize, renew, build and acquire new resources and capabilities. Correspondingly, innovation policy should aim to build and stimulate collective learning processes, in which different functions supporting actual innovation activities are transformed into strategic network-level capabilities of a region. Without these capabilities, there is a risk that regional actors will not be able to induce organisational and institutional change, which will hinder economic renewal of the region.

To make a clear distinction between organizational level resources and networklevel capabilities we particularly emphasized the network-level activities that connect regional actors and knowledge generation, diffusion and exploitation processes. Network-level capabilities have a crucial role in connecting and exploiting regional resources and directing and influencing the regional innovation activities. Embedded in these network-level capabilities and organizational level resources, we also elaborated the importance of dynamic capabilities, which resemble regional networks' constant ability to absorb, adapt and experiment, i.e., to widen and speed up learning and knowledge creation and the exploitation cycle in response to a changing environment. To integrally bring together all aspects, the summary of the capability framework is presented below, in Figure 2.

Figure 2. Summary of the capability framework.

This study and results have important implications for both academics and policymakers. The findings reveal regional capabilities and indicate that studies on 
knowledge-based regional development should pay more attention to the capabilities of the actors involved in the development processes. This research provides a framework for the analytical exploration of knowledge-based development in different kinds of regions and understanding factors that are needed and expected to occur when implementing contemporary innovation policies. With this framework, organizations can better reflect their own capabilities in knowledge-based development and roles in regional networks and recognize in which direction they can and should develop their capabilities.

However, our framework has some limitations which derive from the theoretical framework, the number of interviewees and our subjective interpretation of the discussions and the document data. The theoretical framework has its origins in business economics and organization-level analysis. Thus, even though our framework is based on earlier studies and a strong notion of the applicability of this theory to regional studies, there are still some difficulties of piecing together different elements of the resource-based view. One difficulty is due to heterogeneous terminology. Another important theoretical notion is that in the regional context resources cannot be managed and coordinated through organizational boundaries as straightforwardly as in individual firms and public organizations. Also, some theoretical ambiguities remain on how to distinguish organizational level and network-level attributes.

The set of recognized capabilities represents what attributes and qualities the contemporary innovation activity and policy requires and are expected from the actors involved in these processes. In the future, more comprehensive and comparative (case) studies should be carried out to include diverse regions and a wide range of organizations to verify the applicability and consistency of the framework. Also, one curious aspect would be to examine the links between capabilities and the performance 
of specific regions. A more fundamental question lies in the very essence of innovation policy rationalities, how 'capable' public policymakers can and actually should be influencing innovation activities. 


\section{Bibliography}

Amit, R., \& Schoemaker, P. J. H. (1993). Strategic assets and organizational rent. Strategic Management Journal, 14(1), 33-46. http://doi.org/10.2307/2486548

Asheim, B. T., Boschma, R., \& Cooke, P. (2011). Constructing regional advantage: platform policies based on related variety and differentiated knowledge bases. Regional Studies, 45(7), 893-904. http://doi.org/10.1080/00343404.2010.543126

Asheim, B. T., \& Coenen, L. (2005). Knowledge bases and regional innovation systems: Comparing Nordic clusters. Research Policy, 34(8), 1173-1190. http://doi.org/10.1016/j.respol.2005.03.013

Asheim, B. T., \& Gertler, M. (2005). The geography of innovation: Regional innovation systems,. In J. Fagerberg, D. C. Mowery, \& R. R. Nelson (Eds.), The Oxford Handbook of Innovation (pp. 291-317). Oxford: Oxford University Press.

Barney, J. B. (1991). Firm resources and sustained competitive advantage. Journal of Management. http://doi.org/10.1177/014920639101700108

Bathelt, H., Malmberg, A., \& Maskell, P. (2004). Clusters and knowledge: Local buzz, global pipelines and the process of knowledge creation. Progress in Human Geography, 28(1), 31-56.

Benneworth, P. (2007). Leading Innovation: Building effective regional coalitions for innovation. In Research Report (pp. 1-74). London: Nesta.

Bergek, A., Jacobsson, S., Carlsson, B., Lindmark, S., \& Rickne, A. (2008). Analyzing the functional dynamics of technological innovation systems: A scheme of analysis. Research Policy, 37(3), 407-429. http://doi.org/10.1016/j.respol.2007.12.003

Borrás, S. (2009). The Widening and Deepening of Innovation Policy: What Conditions Provide for Effective Governance? CIRCLE Working Paper 2/2009, 1-28. 
Borrás, S., \& Edquist, C. (2013a). Competence building : A systemic approach to innovation policy. CIRCLE Working Paper 28/2013, 1-38.

Borrás, S., \& Edquist, C. (2013b). The choice of innovation policy instruments. Technological Forecasting and Social Change, 80(8), 1513-1522. http://doi.org/10.1016/j.techfore.2013.03.002

Boschma, R. (2004). Competitiveness of regions from an evolutionary perspective. Regional Studies, 38(9), 1001-1014. http://doi.org/10.1080/0034340042000292601

Carlsson, B. (2007). Innovation systems: A survey of the literature from a Schumpeterian perspective. In H. Hanusch \& A. Pyka (Eds.), Elgar Companion to Neo-Schumpeterian Economics (pp. 857-871). Cheltenham: Edward Elgar Publishing.

Carlsson, B., Jacobsson, S., Holmén, M., \& Rickne, A. (2002). Innovation systems: analytical and methodological issues. Research Policy, 31(2), 233-245. http://doi.org/10.1016/S0048-7333(01)00138-X

Cohen, W. M., \& Levinthal, D. A. (1990). Absorptive capacity: A new perspective on learning an innovation. Administrative Science Quarterly, 35(1), 128-152. http://doi.org/10.2307/2393553

Cooke, P. (1992). Regional innovation systems: Competitive regulation in the new Europe. Geoforum, 23(3), 365-382.

Cooke, P. (2001). Regional innovation systems, clusters, and the knowledge economy. Industrial and Corporate Change, 10(4), 945-974.

Cooke, P. (2005). Regionally asymmetric knowledge capabilities and open innovation. Research Policy, 34(8), 1128-1149. http://doi.org/10.1016/j.respol.2004.12.005 Cooke, P. (2007). To construct regional advantage from innovation systems first build 
policy platforms. European Planning Studies, 15(2), 180-194.

Cooke, P., \& Leydesdorff, L. (2006). Regional development in the knowledge-based economy: The construction of advantage. Journal of Technology Transfer, 31(1), 5-15. http://doi.org/10.1007/s10961-005-5009-3

Cooke, P., \& Morgan, K. (1998). The associational economy: firms, regions, and innovation. Oxford University Press.

Cooke, P., Uranga, M. G., \& Etxebarria, G. (1997). Regional innovation systems: Institutional and organizational dimensions. Research Policy, 26, 475-491. http://doi.org/10.1016/S0048-7333(97)00025-5

Dahlström, M., \& James, L. (2012). Regional policies for knowledge anchoring in European regions. European Planning Studies, 20(October 2012), 1867-1887. http://doi.org/10.1080/09654313.2012.723425

Ebbekink, M., \& Lagendijk, A. (2013). What's next in researching cluster policy: Placebased governance for effective cluster policy. European Planning Studies, 21(5), 735-753. http://doi.org/10.1080/09654313.2013.734460

Edquist, C. (1997). Systems of innovation: Technologies, institutions, and organizations. Pinter. Retrieved from http://books.google.fi/books?id=Sf0POR0ffWEC

Edquist, C. (2011). Design of innovation policy through diagnostic analysis: identification of systemic problems (or failures). Industrial and Corporate Change, 20(6), 1725-1753.

Edquist, C., Luukkonen, T., \& Sotarauta, M. (2009). Broad-based innovation policy. In Evaluation of the Finnish National Innovation System - Full Report. (pp. 11-54). Helsinki: Taloustieto Oy, Helsinki University Print.

Eisenhardt, K. M., \& Martin, J. A. (2000). Dynamic capabilities: what are they? 
Strategic Management Journal, 21, 1105-1121. http://doi.org/10.1002/10970266(200010/11)21:10/11<1105::AID-SMJ133>3.0.CO;2-E

Fagerberg, J., \& Verspagen, B. (2009). Innovation studies - the emerging structure of a new scientific field. Research Policy, 38(2), 218-233.

http://doi.org/10.1016/j.respol.2008.12.006

Flanagan, K., Uyarra, E., \& Laranja, M. (2011). Reconceptualising the "policy mix" for innovation. Research Policy, 40(5), 702-713. http://doi.org/10.1016/j.respol.2011.02.005

Freeman, C. (1987). Technology and economic performance: Lessons from Japan. London, UK: Pinter Publishers.

Grillitsch, M., \& Trippl, M. (2014). Combining knowledge from different sources, channels and geographical scales. European Planning Studies, 22(11), 2305-2325. http://doi.org/10.1080/09654313.2013.835793

Hamel, G., \& Prahalad, C. K. (1996). Competing for the future. Futures, 28, 91-93. http://doi.org/10.1016/S0016-3287(96)90049-X

Harmaakorpi, V. (2004). Building a competitive regional innovation environment - the regional development platform method as a tool for regional innovation policy. Doctoral dissertation series 2004/1, Helsinki University of Technology, Lahti Center.

Ingstrup, M. B., \& Damgaard, T. (2013). Cluster facilitation from a cluster life cycle perspective. European Planning Studies, 21(4), 445-574.

http://doi.org/10.1080/09654313.2012.722953

Javidan, M. (1998). Core competence: What does it mean in practice? Long Range Planning, 31(1), 60-71. http://doi.org/10.1016/S0024-6301(97)00091-5

Kautonen, M. (2006). The regional innovation system bottom-up: a Finnish perspective. 
A Firm-Level Study with Theoretical and Methodological Reflections. Acta Universitatis Tamperensis 1167, Tampere University Press, Tampere.

Kolehmainen, J. (2016). Paikallinen innovaatioympäristö. Kohti alueellisen innovaatiotoiminnan ymmärtämistä. Tampere: Tampere University Press.

Laranja, M. (2012). Network governance of innovation policies: The Technological Plan in Portugal. Science and Public Policy, 39(5), 655-668.

http://doi.org/10.1093/scipol!scs043

Lawson, C. (1999). Towards a competence theory of the region. Cambridge Journal of Economics, 23(2), 151-166. http://doi.org/10.1093/cje/23.2.151

Lawson, C., \& Lorenz, E. (1999). Collective learning, tacit knowledge and regional innovative capacity, 33(4), 305-317. http://doi.org/10.1080/713693555

Lundvall, B.-Å. (1992). National systems of innovation: Towards a theory of innovation and interactive learning. London: Pinter Publishers.

Lundvall, B.-Å., \& Borrás, S. (2005). Science, technology, and innovation policy. In J. Fagerberg, D. C. Mowery, \& R. R. Nelson (Eds.), The Oxford Handbook of Innovation. Oxford: Oxford University Press. (pp. 599-631). Oxford: University Press.

Lönnqvist, A., Käpylä, J., Salonius, H., \& Yigitcanlar, T. (2014). Knowledge that matters: Identifying regional knowledge assets of the Tampere region. European Planning Studies, 22(10), 2011-2029. http://doi.org/10.1080/09654313.2013.814621

Malmberg, A., \& Maskell, P. (2002). The elusive concept of localization economies: Towards a knowledge-based theory of spatial clustering. Environment and Planning A, 34(3), 429-449. http://doi.org/10.1068/a3457

Markusen, A. (2003). Fuzzy concepts, scanty evidence, policy distance: The case for 
rigour and policy relevance in critical regional studies. Regional Studies, 37(6-7), 701-717. http://doi.org/10.1080/0034340032000108796

Martin, R. (2013). Differentiated knowledge bases and the nature of innovation networks. European Planning Studies, 21(9), 1418-1436. http://doi.org/http://dx.doi.org/10.1080/09654313.2012.755836

Martin, R., \& Sunley, P. (2006). Path dependence and regional economic evolution. Journal of Economic Geography, 6(4), 395-437. http://doi.org/10.1093/jeg/lbl012

Martin, R., \& Trippl, M. (2014). System failures, knowledge bases and regional innovation policies. disP - The Planning Review, 50(1), 24-32. http://doi.org/10.1080/02513625.2014.926722

Maskell, P., \& Malmberg, A. (1999). Localised learning and industrial competitiveness. Cambridge Journal of Economics, 23(2), 167-185. http://doi.org/10.1093/cje/23.2.167

Miguélez, E., \& Moreno, R. (2015). Knowledge flows and the absorptive capacity of regions. Research Policy, 44(4), 833-848. http://doi.org/10.1016/j.respol.2015.01.016

Morgan, K. (1997). The learning region: institutions, innovation and regional renewal. Regional Studies, 31(5), 491-503. http://doi.org/10.1080/00343409750132289

Moulaert, F., \& Sekia, F. (2003). Territorial innovation models: A critical survey. Regional Studies, 37(3), 289-302. http://doi.org/10.1080/0034340032000065442

Nelson, R. R., \& Winter, S. G. (1982). An evolutionary theory of economic change. Cambridge MA Belknap (Vol. 93). Cambridge: Harvard University Press. http://doi.org/10.2307/2232409

Penrose, E. (1959). The theory of the growth of the firm. Oxford: University Press. Pihkala, T., Harmaakorpi, V., \& Pekkarinen, S. (2007). The role of dynamic capabilities 
and social capital in breaking socio-institutional inertia in regional development. International Journal of Urban and Regional Research, 31(4), 836-852. http://doi.org/10.1111/j.1468-2427.2007.00757.x

Prahalad, C. K., \& Hamel, G. (1990). The core competence of the corporation. Harvard Business Review, 68, 79-91. http://doi.org/10.1007/3-540-30763-X_14

Sanchez, R., \& Heene, A. (1997). Reinventing strategic management: New theory and practice for competence-based competition. European Management Journal, 15(3), 303-317. http://doi.org/10.1016/S0263-2373(97)00010-8

Saxenian, A. (1994). Regional advantage: culture and competition in Silicon Valley and route 128. Cambridge: Harvard University Press.

Sotarauta, M. (2010). Regional development and regional networks: The role of regional development officers in Finland. European Urban and Regional Studies, 17, 387-400. http://doi.org/10.1177/0969776409352581

Sotarauta, M., \& Beer, A. (2015). Government, agency and place leadership: Lessons from a cross national analysis. In Paper presented in Regional Studies Association European Conference 2015. Piazenca, Italy (forthcoming in Regional Studies) (pp. $1-22)$.

Sotarauta, M., Horlings, L., \& Liddle, M. (Eds.). (2012). Leadership and change in sustainable regional development. Abingdon, UK: Routledge.

Sotarauta, M., \& Kautonen, M. (2007). Co-evolution of the Finnish national and local innovation and science arenas: Towards a dynamic understanding of multi-level governance. Regional Studies, 41(8), 1085-1098.

http://doi.org/10.1080/00343400701292284

Sotarauta, M., \& Kosonen, K.-J. (2013). Customized innovation policies and the regions: digital content services and intelligent machinery in Finland. European 
Urban and Regional Studies, 20, 258-274.

http://doi.org/10.1177/0969776411428499

Storper, M. (1997). The regional world: Territorial development in a global economy (perspectives on economic change). New York: The Guilford Press.

Teece, D. J., Pisano, G., \& Shuen, A. (1997). Dynamic capabilities and strategic management. Strategic Management Journal, 18(7), 509-533. http://doi.org/10.1002/(SICI)1097-0266(199708)18:7<509::AIDSMJ882>3.0.CO;2-Z

Tura, T., Harmaakorpi, V., \& Pekkola, S. (2008). Breaking inside the black box: Towards a dynamic evaluation framework for regional innovative capability. Science and Public Policy, 35(10), 733-744.

http://doi.org/10.3152/030234208X363169

Uyarra, E. (2010). What is evolutionary about " regional systems of innovation "? Implications for regional policy. Journal of Evolutionary Economics, 20, 115-137. http://doi.org/10.1007/s00191-009-0135-y

Uyarra, E., \& Flanagan, K. (2010). From regional systems of innovation to regions as innovation policy spaces. Environment and Planning C: Government and Policy, 28, 681-696. http://doi.org/10.1068/c0961

Vesalainen, J., \& Hakala, H. (2014). Strategic capability architecture: The role of network capability. Industrial Marketing Management, 43(6), 938-950. http://doi.org/10.1016/j.indmarman.2014.05.008

Wang, C. L., \& Ahmed, P. K. (2007). Dynamic capabilities: A review and research agenda. International Journal of Management Reviews, 9(1), 31-51. http://doi.org/10.1111/j.1468-2370.2007.00201.x

Weber, K. M., \& Rohracher, H. (2012). Legitimizing research, technology and 
innovation policies for transformative change. Research Policy, 41(6), 1037-1047. http://doi.org/10.1016/j.respol.2011.10.015

Wernerfelt, B. (1984). A Resource based view of the firm. Strategic Management Journal, 5(2), 171-180. http://doi.org/10.1002/smj.4250050207 